\title{
AR-applications with historical maps
}

\author{
Detlef Günther-Diringer \\ Hochschule Karlsruhe, Detlef Günther-Diringer-Detlef.guenther-diringer@hs-karlsruhe.de
}

Keywords: AR, VR, historical maps, 3D-visualization, game engine

\begin{abstract}
:
In cooperation with the Badische Generallandesarchiv (GLA) Karlsruhe, the officially archive of the former state Baden, various projects in the field of virtual and augmented reality (VR/AR) have been carried out.

The VR project "Danube - Floating Spaces" refers to an exhibition by the GLA Karlsruhe in cooperation with the Institute for Danube Swabian History and Regional Studies, Tübingen. The entire exhibition was constructed in the third dimension and can now be experienced using different devices (offline PC version, WebGL version for Internet access or VR version for the HTC-Vive (VR glasses). An important functionality is the detailed enlargement option of the historical maps, so that many details in the maps can now be seen better than in the original exhibition (Keller 2019). WebGL-version: https://www.hs-karlsruhe.de/gim/angebote-fuer-schueler-und-interessierte/virtuelle-ausstellung.
\end{abstract}

One of the highlights of the map inventory of the GLA is certainly the Great Palatinate Rhine Map from 1590. This handdrawn unique measures approx. $0.45 \mathrm{~m} \mathrm{x} 12 \mathrm{~m}$ and is to be presented in an exhibition in 2021 or 2022. Based on the highquality digital copy available from the GLA, various student projects and theses are currently being carried out to augment digitally this fascinating map. Due to their geometrical-graphic structures, analogue cartographic representations are generally very suitable for performing AR applications. Based on the geographical uniqueness, sections of the maps can be defined as necessary image AR targets, so that the software of a game engine, such as e.g. Unity with the Vuforia extension recognizes that a digital element has to be placed at a specified place. This can be made visible using a tablet or smartphone with a camera. The aim is for visitors of the exhibition to receive additional geographical information with prepared tablets that are held over the map:
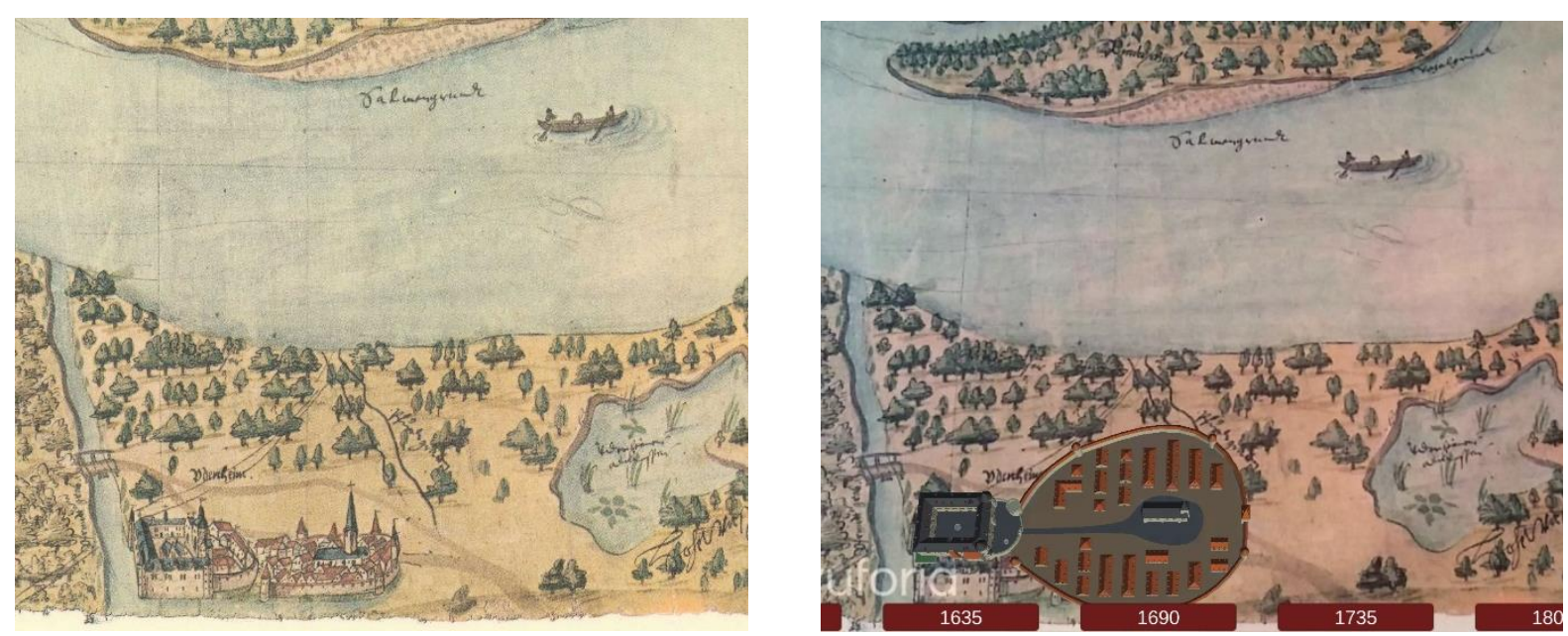

Figure 1: 3D-visualization of the historical development of the fortress Philippsburg (Udenheim in 1590, left: part of the original map, right: with overlayed AR-element).

In addition to the 3D-visualization of 1590 (see figure on the right), the fortifications of the 30 Years War and subsequent extensions are also visible (1635/1690/1735). At that time, Philippsburg was one of the largest fortresses in all of Germany, but it was destroyed by Napoleon around 1800. The final timeline from 1856 is an excerpt from the "Carte from the course of the Rhine" with the straightening of the Rhine through Tulla and shows the significant changes in the landscape that moved the main stream of the Rhine away from Philippsburg (Färber 2019). 


\section{Animated visualizations of pictorial representations:}

In addition to the historical landscapes, the map from 1590 also contains many small pictorial drawings that show human activities during this time, from ferries, fishermen, gold washers to hunters and wine merchants. These drawings were visualized in 3D, animated and, with the help of Unity, placed in the appropriate place. It is intended as a search game for children who can use a tablet and this app to search for more than 20 different scenes on the map and thus experience this historical map in a playful way (Boric 2019):
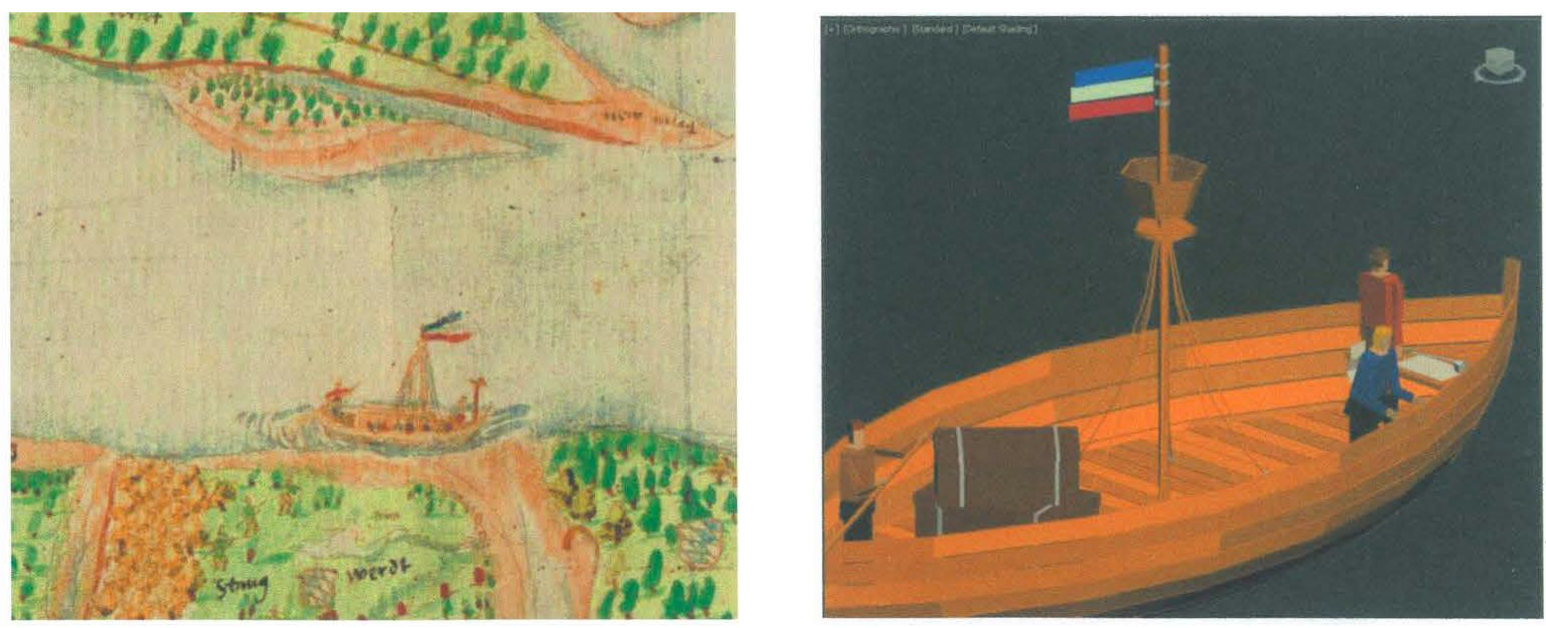

Figure 2: 3D-visualization of a ship on the river Rhine (left: original map, right: 3D-AR-element).

The last project currently planned is the tablet-supported visualization of the landscape changes from the Upper Rhine regulation by Tulla (beginning in the 1820s) until today. On the basis of various historical and current geodata (Rhine river maps 1838/1872, current aerial photos and OpenStreetMap data), the 400-year cultural history of the Upper Rhine between Rastatt and Speyer can be imagined. The georeferencing of the historical map is very challenging. While the maps of the Rhine river from the 19th century are precise in terms of surveying technology, the Great Electoral Palatinate Rhine river map is more of a landscape picture and is far from an exact map representation. Here, the locations of the historical settlements are the only point of reference for a link with the available exact georeferenced geodata. This application will be presented at the exhibition in the GLA in 2021/22.

\section{References}

Boric, Julia (2019): Creation of an augmented reality application for the animated visualization of pictorial content from the large Rhine river map of the Electoral Palatinate from 1590. Bachelorthesis Hochschule Karlsruhe.

Färber, Luise (2019): Augmented Reality 3D-visualization of the Philippsburg Fortress through the ages. Bachelorthesis Hochschule Karlsruhe.

Keller, Felix (2019): Virtualization of a historical map exhibition for selected devices based on the Unity game engine. Bachelorthesis Hochschule Karlsruhe. 